\title{
Evaluation of Human Factors for the User-centered Design of Powered Robotic Transfemoral Prostheses: A Survey of Transfemoral Amputee Experience and Priorities
}

Chiara Fanciullacci

Fondazione Don Carlo Gnocchi

\section{Zach McKinney ( $\sim$ z.mckinney@ieee.org )}

Scuola Superiore Sant'Anna https://orcid.org/0000-0001-7336-9050

\section{Vito Monaco}

Scuola Superiore Sant'Anna

\section{Giovanni Milandri}

IIT: Istituto Italiano di Tecnologia

\section{Angelo Davalli}

Istituto Nazionale Assicurazione Contro gli Infortuni sul Lavoro Direzione Centrale Ricerca

\section{Rinaldo Sacchetti}

Istituto Nazionale Assicurazione Contro gli Infortuni sul Lavoro Direzione Centrale Ricerca

\section{Matteo Laffranchi}

IIT: Istituto Italiano di Tecnologia

\section{Lorenzo De Michieli}

IIT: Istituto Italiano di Tecnologia

\section{Andrea Baldoni}

Scuola Superiore Sant'Anna

\section{Alberto Mazzoni}

Scuola Superiore Sant'Anna

\section{Linda Paternò}

Scuola Superiore Sant'Anna

\section{Elisa Rosini}

Scuola Superiore Sant'Anna

\section{Luigi Reale \\ ISTUD Foundation: Fondazione ISTUD}

\section{Fabio Trecate}

Fondazione Don Carlo Gnocchi

\section{Simona Crea}

Scuola Superiore Sant'Anna

Nicola Vitiello

Scuola Superiore Sant'Anna

\section{Emanuele Gruppioni}

Istituto Nazionale Assicurazione Contro gli Infortuni sul Lavoro Direzione Centrale Ricerca

\section{Research}


Keywords: Transfemoral amputation, lower-limb prostheses, powered prosthesis, user-centered design, human factors, rehabilitation

Posted Date: September 3rd, 2020

DOI: https://doi.org/10.21203/rs.3.rs-68433/v1

License: (c) (i) This work is licensed under a Creative Commons Attribution 4.0 International License. Read Full License 


\section{Abstract}

BACKGROUND: Transfemoral amputees experience a complex host of physical, psychological, and social challenges, compounded by the functional limitations of current transfemoral prostheses. However, the specific relationships between human factors and prosthesis design and performance characteristics have not yet been adequately investigated. The present study aims to address this knowledge gap.

METHODS: A comprehensive single-cohort survey of 114 unilateral transfemoral amputees addressed a broad range of demographic and clinical characteristics, functional autonomy, satisfaction and attitudes towards their current prostheses, and design priorities for an ideal transfemoral prosthesis, including the possibility of active assistance from a robotic knee unit. The survey was custom-developed based on several standard questionnaires used to assess motor abilities and autonomy in activities of daily living, prosthesis satisfaction, and quality of life in lower-limb amputees. Survey data are summarized with descriptive statistics applied separately to users of transfemoral prostheses with versus without microprocessor-controlled knee units (MPKs and NMPKs, respectively).

RESULTS: The cohort featured predominantly younger (< $50 \mathrm{yrs}$.) traumatic male amputees with respect to the general transfemoral amputee population, with pronounced differences in age distribution and amputation etiology (traumatic vs. non-traumatic) between MPK and NMPK groups. These differences were further reflected in user experience, with MPK users reporting markedly greater functional autonomy, satisfaction, and sense of prosthesis ownership than those with NMPKs, in conjunction with a decreased incidence of instability and falls. Across all subjects, the leading functional priorities for an ideal transfemoral prosthesis were overall stability, adaptability to variable walking velocity, and lifestylerelated functionality, while the highest-prioritized general characteristics were reliability, comfort, and weight, with highly variable prioritization of cost.

CONCLUSIONS: This study's findings support the understanding that when appropriately prescribed according to patient characteristics and needs, advanced transfemoral prostheses promote patient mobility, autonomy, and overall health. Survey data indicate overall stability, modularity, and versatility as key design priorities for the continued development of transfemoral prosthesis technology. Finally, observed associations between prosthesis type, user experience, and attitudes concerning prosthesis ownership suggest both that prosthesis characteristics influence device acceptance and functional outcomes, and that psychosocial factors should be specifically and proactively addressed during the rehabilitation process.

\section{Background}

Limb loss imposes numerous physical, psychological, and social challenges on the individual, with a heavy impact on global health and quality of life, thus demanding the development of new strategies for managing daily life and dealing with changes in social relationships (1). Among the approximately 40 million individuals with limb amputations worldwide (2), about 36 million (90\%) are lower-limb amputees (3), of whom an estimated $26 \%$ are transfemoral amputees (TFAs) (4), for whom this host of challenges is compounded by the lack of a natural knee joint.

In this context, the prosthesis plays an essential role both in re-establishing functional autonomy and in substituting the lost limb as part of the individual's body schema. While advances in prosthetic technology over the past decade have greatly increased the availability of powered prosthetic ankles $(5,6)$ and microprocessor-controlled knee units $(7-9)$ for lower-limb amputees, there is presently just one commercially available knee unit (10) providing positive power (as opposed to merely modulating impedance), the adoption of which remains low due to the balance between weight, cost, usability, and functional benefit that it offers for most TFAs. Accordingly, TFAs continue to experience a host of mobility impairments and diminished quality of life $(12,13)$, while achieving lower satisfaction with their prostheses than trans-tibial amputees (11).

Despite the well-recognized importance of psychosocial outcomes such as functional independence (autonomy) and overall quality of life (14), a majority of research and development efforts on advanced transfemoral prostheses (TFPs) to 
date have focused on improving specific technical parameters such as velocity, torque, or power output $(3,15)$, or on the functional performance of the user with the prosthesis (16-18). While several studies have investigated user perceptions specific to single prosthesis characteristics such as cosmetic design (19) or the donning and doffing procedure (20), the precise relationships between TFP design features, functionality, and psychosocial outcomes remain insufficiently understood - and thus insufficiently accounted for in the TFP design process.

In this vein, Beckerle and colleagues (21) have proposed a detailed human-centered approach to lower-limb prosthesis design, with specific attention to the case of TFPs, emphasizing the need for equal consideration of human and technical factors. Though a recent review has consolidated current knowledge on user priorities, design requirements, and clinical guidelines for upper-limb prosthesis selection and prescription (22), such a comprehensive synthesis has not been achieved for TFPs.

The goal of the present study was to address this knowledge gap by illuminating the interplay between human and technical factors for TFP users, via a comprehensive survey of TFP user experience, functional capabilities, and design priorities. In particular, the study aimed i) to characterize TFP users and their subjective experience of current commercial TFPs, and (ii) to identify user design priorities for a new generation of active robotic TFPs that may offer greater functionality, usability, and overall user appeal relative to current commercial prostheses.

\section{Methods}

This study was based on an extensive survey of unilateral transfemoral amputees regarding their subjective experience with their primary prostheses and their priorities regarding the features and functions of an ideal prosthesis, including a positively powered robotic knee unit. The questionnaire was custom-designed in collaboration between the Centro Protesi INAIL (Vigorso di Budrio, Italy), Scuola Superiore Sant'Anna (Pisa, Italy), the ISTUD Healthcare Area Research (Milan, Italy) and the Istituto Italiano di Tecnologia (Genoa, Italy). All study procedures, including subject recruitment and written informed consent were pre-approved by the designated ethics committee for the study sites, in conformance with all pertinent institutional protocols and the Declaration of Helsinki.

\section{A. Questionnaire}

This study's custom questionnaire (Table 1) was developed based on standard questionnaires 


\begin{tabular}{|c|c|c|c|}
\hline Category & Description & Question Items & $\begin{array}{l}\text { Question } \\
\text { Type \& No. }\end{array}$ \\
\hline \multicolumn{4}{|c|}{ Section I. Retrospective Evaluation - User Characteristics and Experience with Current Prosthesis } \\
\hline \multirow[t]{3}{*}{$\begin{array}{l}\text { Participant } \\
\text { description }\end{array}$} & \multirow{3}{*}{$\begin{array}{l}\text { Clinical and demographic } \\
\text { characteristics, and general } \\
\text { description of the amputation } \\
\text { and causes of the limb loss }\end{array}$} & $\begin{array}{l}\text { o Demographic Characteristics: Age, gender, } \\
\text { region of residence, income, level of education } \\
\text { obtained }\end{array}$ & \multirow{3}{*}{$\begin{array}{l}8 \text { multiple- } \\
\text { choice; } \\
4 \text { free } \\
\text { response }\end{array}$} \\
\hline & & $\begin{array}{l}\text { o Amputation \& Clinical Characteristics: year, } \\
\text { anatomical level, side, etiology (traumatic vs. } \\
\text { illness), condition of intact limb, time from } \\
\text { amputation to first prosthesis outfitting }\end{array}$ & \\
\hline & & o Frequency of prosthesis use & \\
\hline \multirow{5}{*}{$\begin{array}{l}\text { Current } \\
\text { prosthesis } \\
\text { description }\end{array}$} & \multirow{5}{*}{$\begin{array}{l}\text { Design features \& details of the } \\
\text { current prosthesis, including the } \\
\text { socket, knee and foot }\end{array}$} & $\begin{array}{l}\text { o Prosthetic knee description: model, type } \\
\text { (electronic vs. modular vs. skeletal) }\end{array}$ & \multirow[t]{5}{*}{$\begin{array}{l}6 \text { free } \\
\text { response }\end{array}$} \\
\hline & & o Prosthetic foot description (model, type) & \\
\hline & & $\begin{array}{l}\text { o Socket support system (ischial seat vs. no } \\
\text { ischial seat) }\end{array}$ & \\
\hline & & o Socket structure (rigid vs. semi-flexible) & \\
\hline & & o Use of socket liner $(\mathrm{Y} / \mathrm{N})$ & \\
\hline \multirow{6}{*}{$\begin{array}{l}\text { Selection and } \\
\text { satisfaction } \\
\text { with current } \\
\text { prosthesis }\end{array}$} & \multirow{6}{*}{$\begin{array}{l}\text { Subjective experience with the } \\
\text { current prosthesis }\end{array}$} & o Patient involvement in prosthesis selection & \multirow{6}{*}{$\begin{array}{l}\text { Likert scale } \\
(1-6) \\
1=\text { low } \\
\text { involvement/ } \\
\text { satisfaction } \\
6=\text { high } \\
\text { involvement/ } \\
\text { satisfaction }\end{array}$} \\
\hline & & $\begin{array}{l}\text { o Satisfaction with Prosthesis Function in ADL } \\
\text { (Sat-Fn; } 12 \text { items) - gait on even and uneven } \\
\text { ground, stairs (up, down), inclines (up, down; } \\
\text { steep, gradual), sit-to-stand and stand-to-sit } \\
\text { transitions, getting in \& out of car, negotiating }\end{array}$ & \\
\hline & & tight spaces & \\
\hline & & $\begin{array}{l}\text { o Satisfaction with Usage \& Maintenance } \\
\text { Characteristics }(6 \text { items) - durability, reliability, } \\
\text { cleanability, water resistance, battery life, } \\
\text { charging time }\end{array}$ & \\
\hline & & $\begin{array}{l}\text { o Satisfaction w. Comfort ( } 3 \text { items) - donning \& } \\
\text { doffing procedure, weight, noisiness }\end{array}$ & \\
\hline & & $\begin{array}{l}\text { o Satisfaction w. Aesthetic Aspects ( } 2 \text { items) - } \\
\text { general appearance, dimensions relative to body }\end{array}$ & \\
\hline \multirow[t]{4}{*}{$\begin{array}{l}\text { Prosthesis } \\
\text { usage in daily } \\
\text { life }\end{array}$} & \multirow[t]{4}{*}{$\begin{array}{l}\text { Perceived autonomy in various } \\
\text { ADL, as well as characterization } \\
\text { of personal activities and } \\
\text { prosthesis usage at home, at } \\
\text { work, and during free time }\end{array}$} & $\begin{array}{l}\text { o Autonomy in ADL: stair ascent, stair descent } \\
\text { (both step-over-step), gait on incline \& decline } \\
\text { (combined), sit-stand transitions (both directions, } \\
\text { combined), bathing, dressing, housework, driving } \\
\text { a car, managing \& observing schedules, } \\
\text { managing free time, attending public places }\end{array}$ & $\begin{array}{l}11 \text { Likert } \\
\text { scale }(1-6) \text { : } \\
1=\text { no } \\
\text { autonomy } \\
\text { (fully } \\
\text { dependent) }\end{array}$ \\
\hline & & $\begin{array}{l}\text { o Current activity at home /work/free time - free } \\
\text { response }\end{array}$ & $\begin{array}{l}6=\text { complete } \\
\text { autonomy }\end{array}$ \\
\hline & & $\begin{array}{l}\text { o Desired activity at home/work/free time - free } \\
\text { response }\end{array}$ & $\begin{array}{l}7 \text { multiple- } \\
\text { choice }\end{array}$ \\
\hline & & $\begin{array}{l}\text { o Time of prosthesis use at home/work/free time } \\
\text { (Likert 1-6) }\end{array}$ & $\begin{array}{l}6 \text { free } \\
\text { response }\end{array}$ \\
\hline
\end{tabular}




\begin{tabular}{|c|c|c|c|}
\hline Category & Description & Question Items & $\begin{array}{l}\text { Question } \\
\text { Type \& No. }\end{array}$ \\
\hline \multirow[t]{2}{*}{ Risk of falls } & \multirow[t]{2}{*}{$\begin{array}{l}\text { Incidence of falls in the last } \\
\text { year and the principal causes of } \\
\text { instability }\end{array}$} & $\begin{array}{l}\text { o Incidence of Falls: No. of falls in past year, main } \\
\text { cause of fall }\end{array}$ & $\begin{array}{l}2 \text { free } \\
\text { response }\end{array}$ \\
\hline & & $\begin{array}{l}\text { o Perceived Causes of Instability: stair ascent; } \\
\text { stair descent; gait on incline (gradual; steep), gait } \\
\text { on decline (gradual; steep), sit-to-stand; stand-to- } \\
\text { sit; "other (describe)" }\end{array}$ & $\begin{array}{l}11 \text { binary } \\
\text { choice }\end{array}$ \\
\hline \multirow[t]{3}{*}{ Pain } & \multirow{3}{*}{$\begin{array}{l}\text { Phantom limb pain } \\
\text { Joint pain in residual limb }\end{array}$} & o Pain frequency (never; a few days a month; a & 4 multiple \\
\hline & & 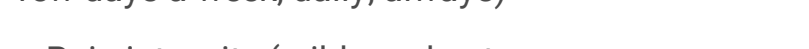 & \\
\hline & & $\begin{array}{l}\text { o Pain intensity (mild; moderate; severe; very } \\
\text { severe; intolerable) }\end{array}$ & \\
\hline \multirow[t]{2}{*}{ Socket } & \multirow{2}{*}{$\begin{array}{l}\text { Skin problems; socket wear- } \\
\text { and-tear and modifications } \\
\text { needed over time }\end{array}$} & Skin problems & \multirow{2}{*}{$\begin{array}{l}2 \text { free } \\
\text { response }\end{array}$} \\
\hline & & Socket modifications (frequency, purpose) & \\
\hline $\begin{array}{l}\text { Subjective } \\
\text { acceptance of } \\
\text { amputee } \\
\text { condition }\end{array}$ & $\begin{array}{l}\text { Patient descriptions of their } \\
\text { feelings about their prostheses }\end{array}$ & 1 free response & \\
\hline \multicolumn{4}{|c|}{ Section II. Prospective Evaluation - User Priorities for an Ideal Prosthesis } \\
\hline $\begin{array}{l}\text { General } \\
\text { characteristics } \\
\text { of the ideal } \\
\text { prosthesis }\end{array}$ & $\begin{array}{l}\text { Priority of characteristics for an } \\
\text { ideal transfemoral prosthesis }\end{array}$ & $\begin{array}{l}\text { Comfort; Reliability; Cost; Weight; Battery life; } \\
\text { Water resistance; Aesthetic aspects; Noisiness; } \\
\text { Cleanability; Transportability }\end{array}$ & $\begin{array}{l}\text { 10-item rank- } \\
\text { order scale }\end{array}$ \\
\hline $\begin{array}{l}\text { Functional } \\
\text { characteristics } \\
\text { of the ideal } \\
\text { prosthesis }\end{array}$ & $\begin{array}{l}\text { Priority of mobility-related } \\
\text { functionality for an ideal } \\
\text { transfemoral prosthesis }\end{array}$ & $\begin{array}{l}\text { Stability, Functionality re: lifestyle, Adaptability to } \\
\text { walking speed, Working activity functionality, } \\
\text { Walking on uneven ground, Stair ascending, } \\
\text { Functioning speed, Stair descending, Ramp } \\
\text { walking, Running }\end{array}$ & $\begin{array}{l}\text { 10-item rank- } \\
\text { order scale }\end{array}$ \\
\hline $\begin{array}{l}\text { Active } \\
\text { assistance the } \\
\text { prosthesis }\end{array}$ & $\begin{array}{l}\text { Moments of instability/balance } \\
\text { loss; Stair ascent; Stair descent; } \\
\text { Natural speed walking; fast } \\
\text { walking; slow walking; Ramp } \\
\text { ascent; Ramp descent; } \\
\text { Standing up and sitting down }\end{array}$ & 10-item rank-order scale & \\
\hline $\begin{array}{l}\text { Adaptive } \\
\text { socket }\end{array}$ & $\begin{array}{l}\text { Preferred features \& charact- } \\
\text { eristics of the ideal socket }\end{array}$ & $\begin{array}{l}\text { Breathable materials; Shape/volume adaptability; } \\
\text { Variable rigidity; Cooling system; Topical drug } \\
\text { release }\end{array}$ & $\begin{array}{l}\text { 5-item rank- } \\
\text { order scale }\end{array}$ \\
\hline
\end{tabular}

assessing motor ability, function in activities of daily living (ADLs), prosthesis satisfaction, and quality of life in amputees, including the Trinity Amputation and Prosthesis Experience Scales-Revised (TAPES) (23), Questionnaire for Persons with a Transfemoral Amputation (Q-TFA) (24), Orthotics and Prosthetics

Users' Survey (OPUS) (25,26), and Prosthesis Evaluation Questionnaire (PEQ) (27). The questionnaire was administered in Italian (native language for all subjects) at a single time point (no follow-up) in one of two ways: i) via in-person interview by a physical therapist, at the Centro Protesi INAIL (Budrio, Italy) and the IRCCS Fondazione Don Gnocchi (Milan, Italy), or ii) via online self-administration.

Summarized in Table 1, the questionnaire consisted of 70 items, addressing four main thematic areas: user characteristics (clinical and demographic), perceived functional abilities and independence with the current prosthesis, user satisfaction and psychosocial experience, and priorities for an ideal prosthesis. User priorities for an ideal prosthesis were divided into 
four sub-categories, namely the general characteristics (Pr-GC), the limb interface socket (Pr-S), the mobility-related functionality ( $\mathrm{Pr}-\mathrm{Fn})$, and the activities that would benefit from receiving active (i.e. positively powered) assistance ( $\mathrm{Pr}-\mathrm{AA})$. Across all sections, survey items comprised a mix of question types, including multiple choice, Likert scale (1-6), rank ordering (1-10), and free written response.

\section{B. Study Population: Eligibility and Inclusion}

Subject eligibility was defined to include adult (age 18-79) unilateral TFAs, recruited from the patient populations at the participating rehab centers, as well as via online recruitment through their affiliated patient support networks on social media. Of surveys completed, selective response omissions were allowed, according to the user's judgement of applicability to their case, while surveys with large blocks or whole sections of missing responses were omitted.

\section{Data Analyses}

Numeric survey data were summarized using quantitative descriptive statistics appropriate to each data type (continuous, categorical, ordinal), with ordinal data reported as median (inter-quartile range, IQR). Based on the study objective of informing the design of an advanced robotic TFP, participants were grouped for analysis according to primary prosthesis type: those with electronic (i.e. microprocessor-controlled) knee units (MPKs), and those with purely mechanical (i.e. nonmicroprocessor-controlled) knees (NMPKs), including hydraulic knees. To address observed demographic differences between groups in terms of age and amputation etiology, autonomy data analysis was further stratified into traumatic and non-traumatic amputation sub-groups. All quantitative data analysis was conducted using Excel, SPSS, and MATLAB softwares.

Free response data were analyzed qualitatively using the thematic analysis technique described by Braun and Clarke (28), which provides a theoretically flexible approach to analyze qualitative data for key descriptive information concerning the guiding research questions. Using this technique, thematic categories related to user perceptions of their prostheses and their functional abilities were identified, and responses were then semantically classified into sentiment clusters corresponding to the identified themes.

\section{Results}

\section{A. Demographic and Clinical Characteristics}

A total of 114 correctly completed questionnaires were obtained from unilateral TFA participants from the 189 surveys administered (based on available recruitment capacity) during the period of February-April, 2018, with 75 excluded for incompleteness or failure to meet inclusion criteria (e.g. trans-tibial amputees). Summarized in Table 2, the final subject sample comprised mostly males (88\%), with a median (IQR) age of 50 (15) years and unilateral amputations occurring at a median age of 30 (22.5; mean 33.2) years, corresponding to 16.5 (26.3; mean 17.1) years since amputation. Among all subjects, $26.3 \%$ of amputation cases were semi-acute $(\leq 2 \mathrm{yr}), 8.8 \%$ recent $(2-5 \mathrm{yr})$, and $64.9 \%$ chronic $(>5 \mathrm{yr})$. 
Table 2

Clinical demographics of study cohort, by group.

\begin{tabular}{|c|c|c|c|c|}
\hline Variable & $\begin{array}{l}\text { Overall } \\
(\mathrm{N}=114)\end{array}$ & $\begin{array}{l}\text { NMPK } \\
(n=45)\end{array}$ & $\begin{array}{l}\text { MPK } \\
(n=69)\end{array}$ & \\
\hline \multicolumn{5}{|l|}{ Amputation Etiology } \\
\hline Traumatic & $90(78.9 \%)$ & $27(60 \%)$ & $63(91.3 \%)$ & \multirow[t]{5}{*}{$\mathrm{n}(\%)^{\star}$} \\
\hline Non-traumatic & $24(21.1 \%)$ & $18(40 \%)$ & $6(8.7 \%)$ & \\
\hline \multicolumn{4}{|l|}{ Gender } & \\
\hline Men & $88(77.2 \%)$ & $30(66.7 \%)$ & $58(84.1 \%)$ & \\
\hline Women & $22(19.3 \%)$ & $14(31.1 \%)$ & $8(11.6 \%)$ & \\
\hline Age $(y r)$ & $50(15)$ & $51(22)$ & $49.5(13)$ & \multirow[t]{4}{*}{ Med (IQR) } \\
\hline Age at amputation $(y r)$ & $30(22.5)$ & $39(31.5)$ & $29(21)$ & \\
\hline Time since amputation $(y r)$ & $16.5(26.3)$ & $4.5(19)$ & $19.5(26.8)$ & \\
\hline Time from amputation to $1^{\text {st }}$ TFP (mo.s) & $6(5)$ & $6(5.25)$ & $6(4)$ & \\
\hline
\end{tabular}

The main features of the participants' current prostheses are detailed in Table 3. Those using MPKs and NMPKs (respectively) as their primary prostheses were comparable in age and time between amputation and receipt of the first prosthesis, though pronounced between-group differences were noted in amputation etiology, age at the time of amputation, and time since amputation, with MPK users having suffered a greater proportion of traumatic amputations, typically at younger ages. 
Table 3

Transfemoral prosthesis (TFP) characteristics, by group.

\begin{tabular}{|llll|}
\hline Characteristic & $\begin{array}{l}\text { Overall } \\
(\mathrm{N}=114)\end{array}$ & $\begin{array}{l}\text { NMPKs } \\
(\mathrm{n}=45 ; 40 \%)\end{array}$ & $\begin{array}{l}\text { MPKs } \\
(\mathrm{n}=69 ; 60 \%)\end{array}$ \\
\hline Prosthetic foot type & & & \\
\hline SACH & $8(7 \%)$ & $6(13.3 \%)$ & $2(2.9 \%)$ \\
\hline Articulated (Single or Multi-Axis) & $15(13.2 \%)$ & $7(15.6 \%)$ & $8(11.6 \%)$ \\
\hline Carbon fiber & $71(62.3 \%)$ & $22(48.9 \%)$ & $49(71 \%)$ \\
\hline Missing/other & $20(17.5 \%)$ & $10(22.2 \%)$ & $10(14.5 \%)$ \\
\hline Socket support system & & & \\
\hline Ischial support & $68(59.6 \%)$ & $23(51.1 \%)$ & $45(65.2 \%)$ \\
\hline Ischial containment & $35(30.7 \%)$ & $15(33.3 \%)$ & $20(29 \%)$ \\
\hline Missing/other & $9(9.7 \%)$ & $7(15.6 \%)$ & $4(5.7 \%)$ \\
\hline Socket structure frame & & & $19(1.4 \%)$ \\
\hline Entirely rigid & $38(33.3 \%)$ & $19(42.2 \%)$ & $19(27.5 \%)$ \\
\hline Windows (semi flexible) & $71(62.3 \%)$ & $21(46.7 \%)$ & $50(72.5 \%)$ \\
\hline Missing/other & $5(4.4 \%)$ & $5(11.1 \%)$ & 0 \\
\hline Liner & $51(53.5 \%)$ & $22(48.9 \%)$ & $39(56.5 \%)$ \\
\hline Yes & $48(42.1 \%)$ & $19(42.2 \%)$ & $29(42 \%)$ \\
\hline No & $5(4.4 \%)$ & $4(8.9 \%)$ & 10 \\
\hline Missing & & & \\
\hline & & & \\
\hline
\end{tabular}

\section{B. User Experience \& Satisfaction}

\section{B.1. Functional Capabilities \& Independence}

Independent Prosthesis Usage (Table 4). Reported prosthesis utilization was high across all participants, with a median (IQR) usage frequency of 7(0) days per week in both groups, and with MPK users indicating greater daily use of the prosthesis. This difference varied by context, with both groups reporting comparably high usage at work/school, but MPK users reporting greater usage at home and in recreational settings. MPK users also noted greater involvement in the prosthesis selection process. 
Table 4

Utilization of current prosthesis

\begin{tabular}{|c|c|c|c|}
\hline Variable & $\begin{array}{l}\text { Overall } \\
(\mathrm{N}=114)\end{array}$ & $\begin{array}{l}\text { NMPK } \\
(n=45)\end{array}$ & $\begin{array}{l}\text { MPK } \\
(n=69)\end{array}$ \\
\hline & \multicolumn{3}{|c|}{ Median (IQR) } \\
\hline Involvement in prosthesis selection ${ }^{a}$ & $5(3.5)$ & $4(3)$ & $6(1)$ \\
\hline \multicolumn{4}{|l|}{ Prosthesis Utilization } \\
\hline Days per week & $7(0)$ & $7(0)$ & $7(0)$ \\
\hline Hours per day & $14(6)$ & $10(7)$ & $15(2)$ \\
\hline \multicolumn{4}{|l|}{ Time of Use $\mathrm{e}^{\mathrm{b}}$} \\
\hline At work/school & $5.0(0)$ & $5.0(2)$ & $5.0(0)$ \\
\hline At home & $5.0(2)$ & $3.0(3.5)$ & $5.0(1)$ \\
\hline In free time (community activities \& hobbies) & $5.0(1)$ & $4.0(3)$ & $5.0(0)$ \\
\hline
\end{tabular}

Autonomy. Perceived autonomy for various ADLs is depicted in Figure 1, with the consistent trend that MPK users qualified themselves as more autonomous than NMPK users in all tasks. While a majority of MPK users rated themselves as fully autonomous in all tasks except for stair ascent, NMPK autonomy ratings varied more widely by task, with predominantly non-autonomous ratings (median score $\leq 3$ of 6 ) in the tasks of stair ascent, descent, and ramp walking. Notably, a majority of TFP users in both groups reported full functional autonomy in the tasks of dressing, bathing, driving a car, and schedule management. Concerning amputation etiology, stratified analyses within the traumatic and non-traumatic amputee sub-groups found the differences between MPK and NMPK users to remain evident for a majority of ADLs (Table 5), with notably more pronounced differences within the non-traumatic sub-group (median (IQR) aggregate autonomy 6(2) for $\mathrm{MPK}_{\mathrm{NT}}$ vs. 3(2) $\left.\mathrm{NMPK}_{\mathrm{NT}}\right)$. 
Table 5

Autonomy in ADL - stratified by amputation etiology

\begin{tabular}{|c|c|c|c|c|}
\hline \multicolumn{5}{|c|}{ "To what extent are you autonomous in the following activities?" } \\
\hline \multirow[t]{2}{*}{ Activity } & NMPK $_{\mathrm{Tr}}$ & $\mathrm{MPK}_{\mathrm{Tr}}$ & $\mathrm{NMPK}_{\mathrm{NT}}$ & $\mathrm{MPK}_{\mathrm{NT}}$ \\
\hline & \multicolumn{2}{|c|}{ Median score ${ }^{a}(\mathrm{IQR})$} & \multicolumn{2}{|c|}{ Median score ${ }^{a}(\mathrm{QQR})$} \\
\hline Stair ascending & $3(3)$ & $4(5)$ & $1(1)$ & $2.5(2.5)$ \\
\hline Stair descending & $3(3)$ & $6(2)$ & $1(1)$ & $6(1.5)$ \\
\hline Ramp walking & $4(2)$ & $6(2)$ & $2(2)$ & $6(1.5)$ \\
\hline Sit-to-stand/Stand-to-sit & $4(2.75)$ & $6(0)$ & $3(2)$ & $6(0)$ \\
\hline Bathing & $6(2)$ & $6(0)$ & $3.5(4)$ & $6(0)$ \\
\hline Dressing & $6(1.5)$ & $6(0)$ & $4(3)$ & $6(0)$ \\
\hline House work & $4(3)$ & $6(2)$ & $3(3)$ & $6(2.25)$ \\
\hline Driving a car & $6(0)$ & $6(0)$ & $1(2)$ & $6(0)$ \\
\hline Schedule management & $6(0.5)$ & $6(0)$ & $3(5)$ & $5(2)$ \\
\hline Management of free time & $6(2)$ & $6(0.5)$ & $3(1.5)$ & $4(2.25)$ \\
\hline Attending public places & $6(2)$ & $6(0)$ & $3(2.75)$ & $6(0)$ \\
\hline Aggregate $^{\mathrm{b}}$ & $6(2)$ & $6(0)$ & $3(2)$ & $6(2)$ \\
\hline \multicolumn{5}{|c|}{$\begin{array}{l}\text { a. Values reported on Likert scale from } 1 \text { (fully dependent, not autonomous) to } 6 \text { (fully autonomous); Reported } \\
\text { separately for traumatic (Tr) and non-traumatic (NT) with and without microprocessor-controlled knees (MPKs), } \\
\text { respectively; }\end{array}$} \\
\hline
\end{tabular}

Falls. $72 \%$ of the whole group ( $80 \%$ NMPK vs. $67 \%$ MPK) reported at least one fall within the past year, with stair descent and steep ramp descent cited as the most frequent situational causes of instability (Table 6). Steep ramp ascent and gradual slope descent were also cited as common causes of instability by both groups, while the greatest difference in the attribution of instability between groups was for other (miscellaneous) causes, cited by more MPK (19\%) than NMPK users (3\%). Whereas NMPK users most commonly attributed their falls to the aforementioned environmental factors associated with instability, MPK users typically attributed falls to personal errors and controllable factors such as "distraction", "tripping", and "rapid movements." 
Table 6

Falls and situational causes of instability

\begin{tabular}{|llll|}
\hline Variable & $\begin{array}{l}\text { Overall } \\
(\mathrm{N}=114)\end{array}$ & $\begin{array}{l}\text { NMPK } \\
(\mathrm{n}=45)\end{array}$ & $\begin{array}{l}\text { MPK } \\
(\mathrm{n}=69)\end{array}$ \\
\hline Falls within the past year & & & \\
\hline Yes & $82(72 \%)$ & $36(80 \%)$ & $46(67 \%)$ \\
\hline No & $29(25 \%)$ & $8(18 \%)$ & $21(30 \%)$ \\
\hline missing & $3(3 \%)$ & $1(2 \%)$ & $2(3 \%)$ \\
\hline Situations of Perceived of Instability_('select all that apply_). & $3(5)$ \\
\hline Stair ascent & $8(7 \%)$ & $5(8 \%)$ & $12(21 \%)$ \\
\hline Stair descent & $26(22 \%)$ & $14(23 \%)$ & $6(10 \%)$ \\
\hline Ramp ascent (steep) & $16(13 \%)$ & $10(16 \%)$ & $14(24 \%)$ \\
\hline Ramp descent (steep) & $28(24 \%)$ & $14(23 \%)$ & $14(5 \%)$ \\
\hline Slope ascent (gradual) & $7(6 \%)$ & $4(7 \%)$ & $3(9 \%)$ \\
\hline Slope descent (gradual) & $12(10 \%)$ & $7(11 \%)$ & $5(3 \%)$ \\
\hline Sitting down & $4(3 \%)$ & $2(3 \%)$ & $2(3 \%)$ \\
\hline Standing up & $5(4 \%)$ & $3(5 \%)$ & $11(19 \%)$ \\
\hline Other & $13(11 \%)$ & $2(3 \%)$ & \\
\hline
\end{tabular}

\section{B.2. Prosthesis Satisfaction \& Psychosocial Experience}

Satisfaction with the current prosthesis is summarized in Table 7 for the four categories of prosthesis functionality, comfort, aesthetics, and general characteristics \& maintenance, with MPK users reporting greater global satisfaction in all categories, with full response distributions regarding ADL-specific prosthesis functionality depicted in Figure 2. Of particular note, across all subjects, the difference in satisfaction between MPK and NMPK users was least pronounced for stair ascent, the ADL with the lowest satisfaction score for both groups. 
Satisfaction with the current prosthesis

\begin{tabular}{|c|c|c|c|}
\hline Variable & Overall & NMPK & MPK \\
\hline Satisfaction Rating & \multicolumn{3}{|c|}{ Median (IQR) ${ }^{\mathrm{a}}$} \\
\hline Comfort* & $5.0(2)$ & $4.0(1)$ & $5.0(1)$ \\
\hline Donning and doffing & $5.0(2)$ & $4.0(2.25)$ & $5.0(1)$ \\
\hline Weight & $4.0(2)$ & $4.0(2)$ & $4.0(1)$ \\
\hline Noisiness & $6.0(1)$ & $5.0(2)$ & $6.0(1)$ \\
\hline Aesthetic aspects* & $5.0(2)$ & $4.0(1.5)$ & $5.0(1.5)$ \\
\hline General appearance & $5.0(2)$ & $4.0(2)$ & $5.0(2)$ \\
\hline Size/dimensions relative to body & $5.0(2)$ & $4.0(2)$ & $5.0(2)$ \\
\hline Functionality* & $4.5(1.5)$ & $4.0(2.25)$ & $5.0(1.5)$ \\
\hline Gait & $5.0(2)$ & $5.0(1)$ & $5.0(1)$ \\
\hline Gait on irregular surfaces & $4.0(2)$ & $4.0(2)$ & $5.0(2)$ \\
\hline Stair ascent & $3.0(2)$ & $3.0(2)$ & $3(2.25)$ \\
\hline Stair Descent & $5.0(3)$ & $3.0(3)$ & $5.0(2)$ \\
\hline Stand-to-sit transitions & $4.0(3)$ & $4.0(2)$ & $5.0(2)$ \\
\hline Sit-to-stand transitions & $4.0(2)$ & $4.0(2)$ & $5.0(2)$ \\
\hline Ascent of gradual incline (ramp) & $4.0(2)$ & $4.0(1.75)$ & $5.0(2.25)$ \\
\hline Descent of gradual decline (ramp) & $5.0(2)$ & $4.0(3)$ & $5.0(1)$ \\
\hline Ascent of steep incline (ramp) & $3.0(2)$ & $3.0(2.75)$ & $4.0(3)$ \\
\hline Descent of steep decline (ramp) & $4.0(3)$ & $3.0(3)$ & $5.0(2)$ \\
\hline Getting in and out of automobile & $4.5(2)$ & $4.0(3)$ & $5.0(3)$ \\
\hline Maneuvering in tight spaces & $4.0(3)$ & $3.0(2)$ & $4.5(2)$ \\
\hline General Characteristics \& Maintenance* & $5.0(2)$ & $5.0(1.0)$ & $5.5(1)$ \\
\hline Cleanability & $5.0(2)$ & $4.0(2)$ & $6.0(1)$ \\
\hline Robustness & $5.0(2)$ & $5.0(1.5)$ & $5.0(1)$ \\
\hline Water Resistance & $3.0(4)$ & $3.0(4)$ & $3.0(4)$ \\
\hline Reliability & $5.0(2)$ & $5.0(2)$ & $5.0(1)$ \\
\hline Battery autonomy & $5.0(2)$ & $\mathrm{N} / \mathrm{A}$ & $5.0(2)$ \\
\hline Battery charging time & $6.0(1)$ & $\mathrm{N} / \mathrm{A}$ & $6.0(1)$ \\
\hline
\end{tabular}

Subjective Acceptance \& Body Integration. Thematic analysis of free responses to the question "what is the prosthesis for you?" revealed 3 semantic categories: "tool", describing the TFP as a means to obtain a functional result; "part of me", 
describing it as a naturalistic part of the body; and "obstacle/noise", as an impediment to daily life. Across all subjects, approximately half ( $51 \%$ overall; $49 \%$ MPK; $53 \%$ NMPK) described the TFP as a "tool", $38 \%$ as "part of me", and only $6 \%$ as an obstacle. Notably, substantially more MPK than NMPK users (46\% vs. $29 \%$ ) characterized their prostheses as "part of me", corresponding to more NMPK users (13\% vs. $1 \%$ MPK) considering their prostheses an obstacle/noise. $4 \%$ of MPK and $5 \%$ of NMPK subjects did not complete this question item.

\section{Design priorities for an ideal transfemoral prosthesis (TFP)}

User priority rankings for the features and functions of an ideal TFP are summarized in Error! Reference source not found. for all four design categories evaluated by the questionnaire. For general prosthesis characteristics (Pr-GC), reliability, comfort, and prosthesis weight scored as the highest-ranked items for both the NMPK and MPK groups, with cost ranking fourth. Regarding functional mobility (Pr-Fn), overall prosthesis stability was the highest-rated priority for the whole sample, with NMPK users ranking it nearly unanimously in the first position and MPK users placing it only slightly ahead of lifestylerelated functionality. Walking speed adaptability ranked as the third priority for both groups, while MPK users expressed a higher preference towards walking on uneven terrain.

Regarding contexts for active assistance from the prosthesis ( $\mathrm{Pr}-\mathrm{AA}$ ), moments of instability were ranked highest by both groups, though no task earned an $\mathrm{mRO}$ of 1 due to high individual variability. The greatest between-group differences in PrAA were relative to stair ascent, ramp ascent, and high-speed walking -all ranked higher by MPK users- as well as sit-tostand transitions, given greater preference by NMPK users. Regarding the prosthetic socket (Pr-S), both groups prioritized 1) socket adaptability to the residuum shape and volume, 2) the use of breathable materials, and 3) variable socket stiffness, differing only regarding an active cooling system, ranked slightly higher by MPK users.

\section{Discussion}

The current study data provide a transverse characterization of transfemoral prosthesis (TFP) users, their experience and satisfaction with their current prostheses, and their priorities for an ideal prosthesis, from which we can draw numerous insights pertinent to the user-centered design of technologically-advanced TFPs.

\section{A. User Characteristics}

The present study cohort presented a range of ages, lifestyles, limb loss etiologies, and social demographics, reflecting the diversity TFA population. A significant feature of the subject sample was the predominance (78.9\%) of traumatic causes of amputation, differing markedly from the estimated $16.4 \%$ of total lower-limb amputations (4). In addition to potential differences in the prevalence of transfemoral vs. below-knee cases among traumatic vs. non-traumatic amputations, the predominance of traumatic and male amputees likely represents a recruitment bias at the primary survey administration site, the INAIL Prosthetic Center - a rehabilitation center for patients with work-related disabilities- an effect reported in previous studies with a predominance of TFAs (19).

Given the difference in amputation etiology distribution between the MPK and NMPK groups, the observed differences in age at amputation and time since amputation may be partially attributable to the contrasting clinical circumstances and pre-amputation lifestyles commonly associated with traumatic vs. non-traumatic (typically dysvascular) amputations. Whereas traumatic amputations are commonly associated with accidents during rigorous physical activity, non-traumatic amputations are overwhelmingly the result of vascular disease occurring secondary to many years of chronic metabolic diseases such as type II diabetes (29), which is strongly associated with sedentary lifestyles.

\section{B. User Experience \& Satisfaction}


In aggregate, our survey data indicated consistently that subjects with MPKs use their prostheses more frequently, experience a greater sense of autonomy, and are overall more satisfied with their devices than those with NMPK-TFPs. Specific notable findings and implications are discussed below, by category.

Achieving independence in ADLs and a corresponding sense of personal autonomy is a primary clinical objective of prosthesis use, to which end regular, independent prosthesis usage in a range of activities and environments is instrumental $(14,30-32)$. The positive correspondence between greater daily prosthesis utilization and greater autonomy among MPK vs. NMPK users in the current study (Table 4) affirms this picture. Moreover, the greater prosthesis usage by MPK users in home and recreational but not work/school environments implies both that MPKs effectively fulfill functional user needs over a wider range of activities than NMPKs and that they promote a greater overall level of activity.

Regarding the distribution of reported autonomy between groups, NMPK users exhibited greater variance relative to MPK users (Figure 1 - IQR), both within individual ADLs and across all ADLs. In addition to reflecting potentially greater diversity in the NMPK user population, the tighter and more favorable autonomy distribution among MPK users suggests that MPK use may have a positive influence in equalizing functional outcomes across a wide range of baseline user health characteristics. Moreover, the persistence of greater autonomy among MPK vs. NMPK users within both the demographically self-similar traumatic and non-traumatic sub-groups (Table 5) suggests that the prosthesis plays a significant role in facilitating autonomy, in concert with personal and clinical co-factors. In particular, the dramatic differences in median autonomy between MPK and NMPK users with non-traumatic amputations for all $A D L$ suggests that patients with lower baseline health and/or functional capabilities may draw additional clinical benefit from the use of technologically advanced TFPs. By contrast, the positive differences in autonomy associated with MPK use among traumatic amputees were generally subtler (often evident in the variance rather than the median) and more task-specific, with the greatest differences observed for the more challenging tasks of stair descent, sit-stand transitions, and ramp walking, in addition to house work.

In sum, the observed differences in autonomy affirm a worrisome discrepancy in outcomes between TFA sub-populations that may be addressable with more advanced, more accessible, and/or more usable TFPs.

As a concrete clinical outcome complementary to subjective autonomy, the markedly higher incidence of falls among NMPK users in the present study must likewise be considered within a complex interplay of technical and clinical factors. In particular, fall risk among lower-limb amputees has been previously related to various biomechanical factors, including gait asymmetry, muscle weakness, and other neuro-musculoskeletal limitations $(33,34)$, as well as to environmental factors such as irregular terrain, stairs, and slopes $(35,36)$. The prosthesis plays a crucial role in safely negotiating these 'challenge scenarios,' with previous studies showing that the use of MPK prostheses can improve motor functions and reduce falls in amputees with lower mobility grades $(37,38)$, in addition to promoting greater overall movement control, dynamic stability, and functional mobility $(3,12,39)$. Significantly, these and other functional performance parameters such as walking speed various surfaces, incidence of stumbles and falls, and stair descent ability have all been linked with overall amputee satisfaction, wellbeing, and quality of life $(12,37,38,40)$.

The current study findings thus reinforce an integrated clinical picture in which technologically-advanced TFPs can be powerful tools in promoting user mobility and autonomy, but one that must be employed as part of a comprehensive rehabilitation paradigm that emphasizes functional training in addition to proactive psychological support. Further evidence for such an integrated approach is found in this study's observation that users of MPKs, via their common attribution of falls to personal and attentional rather than environmental or technical factors, exhibited a higher degree of control and ownership of their prostheses thus highlighting the symbiotic relationship between psychological factors and functional outcomes. Based on the preponderance of past and present evidence, it is reasonable to infer that more advanced TFPs can be more effective than traditional TFPs at realizing user potential that depends simultaneously on various health and dispositional factors, and that thoughtful prosthesis selection and configuration based on individual user needs will thus remain necessary to maximizing the benefit of such devices.

Page 15/25 
This study's principal finding that strong majorities of TFP users in both groups regarded their prostheses either as useful tools for achieving personal autonomy or as extensions of their bodies is a positive indicator of successful functional rehabilitation and prosthesis acceptance in the study population. Moreover, the increased sense of anatomical ownership expressed by MPK users suggests that both naturalistic prosthesis function and the experience of using it in a synergistic manner may contribute strongly to the sense of body schema integration and corresponding acceptance. This implication echoes previous studies that have identified human interaction as a strong factor in improving the subjective sense of control of the artificial leg, thus enhancing the performance and management of ADLs $(21,41)$.

This study's observation of higher prosthesis satisfaction among MPK relative to NMPK users in all four categories of functionality, comfort, aesthetics, and general characteristics aligns with previous research that has found overall satisfaction to be influenced by several aspects of the prosthesis, including functionality, cosmetics, and usability $(22,32)$. While it may be expected that traumatic amputees (accounting for $91 \%$ of the MPK group, vs. just $60 \%$ of NMPKs) tend to be more functionally capable than those with dysvascular amputations by virtue of better overall health, it may likewise be true that less healthy and less active individuals have lower mobility demands and/or expectations, thus making the net effect of prosthesis type on satisfaction unclear a priori. This complexity implies both that TFPs should be designed with more than bare-minimum functional autonomy requirements in mind (especially with respect to gait), and also that user satisfaction can be positively influenced by psychological counseling featuring proactive management of expectations and attitudes, regardless of prosthesis type. In sum, the positive association between functional, practical, and aesthetic dimensions of prosthesis satisfaction further reinforces that the benefits of higher-performing TFPs extend beyond purely functional outcomes and encompass overall user satisfaction and wellness.

\section{Priorities for an Ideal Transfemoral Prosthesis (TFP)}

Given the critical role of device design in prosthesis usability and user satisfaction, the evaluation of user priorities represents an indispensable foundation of the TFP design process. Design priorities reflect the user's values, lifestyle, and goals for prosthesis use, which have been found to vary significantly by prosthesis type and user age in upper limb prostheses (32). While the median user priorities in the current study likewise varied between MPK and NMPK users, the magnitude and significance of these differences appear secondary to the high variation in priorities between individuals, reflecting the diversity in subjects' demographic/clinical characteristics, functional ability, and autonomy evidenced by other survey sections. Despite the high variance in user priorities for specific features, common high-level groupings of priorities across all subjects remain pertinent and informative to TFP design.

Priorities for functional mobility (Pr-Fn). The prevailing functional priority of general stability across all TFP users agrees with previous findings among MPK users (38). Here, NMPK users were more consistent in ranking stability first, whereas MPK users expressed a comparably strong preference for stability and lifestyle adaptability. Given that MPK users reported significantly greater overall autonomy and satisfaction with functional mobility than NMPK users, this subtle difference suggests that design priorities are influenced both by user lifestyle (actual and desired), and also by user perceptions about the limitations of their current prostheses relative to their expectations of device capability. Moreover, we note that the highest-ranked functions were those applicable to a range of situations (overall stability, lifestyle-related functionality, adaptability of walking velocity), with more specific tasks of gait on uneven terrain, stair ascent, and ramp walking (up and down) falling in the second tier. Based on our analysis of free responses, "lifestyle functionality" was interpreted by subjects in a variety of ways (some more task-specific than others), thus rendering this priority interpretable in aggregate as a measure of the need for TFP versatility and adaptability to different tasks and environments.

Notably, "work-related functionality" represents an exception to the trend towards favoring versatility, ranking as a moderateto-lower priority for both groups. The distinction in preference for lifestyle over work-related functionality is difficult to parse, given that the functional demands of lifestyle and work environments are not easily generalizable, nor discernible from 
survey data. What may be inferred regardless is that TFP users consider the ability to maintain their desired personal lifestyle a more important determinant of their satisfaction than their vocational ability.

Priorities for Active Assistance (Pr-AA). Overall, TFP user priorities for AA agree well with those for functional mobility, with the top functional priority of overall stability corresponding to the preference for AA during moments of instability. Likewise, the trend towards prioritization of ascent vs. descent functions corresponded to the preference for AA in those tasks. The prioritization of locomotion velocity provides a more nuanced picture: while the high prioritization of adaptability to walking velocity corresponds functionally to the preference for active assistance during fast versus natural versus slow speed walking, the highest speed form of locomotion - running - was among the least prioritized functionalities by both groups. This finding indicates that high speed walking differs significantly from running in terms of its personal value to users perhaps owing to a difference in social utility. Given the unique biomechanical demands of running, the elimination of this function as a TFP design requirement would enable a valuable simplification in TFP design.

Regarding the future design and development of advanced TFPs, we note that for both gait speed and ascending vs. descending functions, user priorities for AA reflected the biomechanical demands of the highest-priority mobility functions, with preference to tasks demanding greater positive power output. By contrast, controlled descent and lower-speed gait are more easily achieved via the modulated resistance achievable by current MPKs. This high-level correspondence between priorities for $\mathrm{AA}$ and for overall prosthesis functionality suggests that these categories may be strategically merged into a single class of design requirements. In line with user-centered design recommendations from the fields of both lower-limb prosthesis design (21) and brain-computer-interface-based assistive technology (42), such a design process should focus first on defining user priorities regarding the desired tasks and activities to be performed with the prosthesis, based on user input.. Specific technical requirements such as active knee power should then be defined based on the biomechanical and ergonomic demands of those tasks, so as to enable users to perform their highest-priority activities in a safe, effective, and efficient manner.

Priorities for General and Socket Characteristics (Pr-GC; Pr-S). Current MPK and NMPK users expressed very similar priorities regarding both general device characteristics and socket design. Primary between-group differences in Pr-GC tended to concern more technical, higher-performance TFP traits such as battery life and water resistance, which likely reflects a difference in applicability of various traits to the user's TFP rather than a fundamental difference in priority. Similarly, the only pronounced difference in Pr-S was the elevated preference for active-cooling by MPKs users, which is likely attributable to higher activity levels in this group, which would naturally result in more frequent sweating and residuum volume changes. The consistency of socket-related priorities across groups supports the modular design of high-performance sockets that are compatible with a wide range of prosthetic knee types, suitable to a range of activity levels, based on user lifestyle.

\section{Application to User-Centered Design of TFPs}

Following from the above discussion, this study's findings may be synthesized into the following essential user-centered design principles for an ideal TFP:

- The safety and reliability of the TFP across a wide range of ADLs are fundamental design priorities for all TFA users, regardless of prosthesis type, demographic characteristics, and amputation etiology.

- Individual user needs and priorities vary significantly based on clinical characteristics, personal attitudes, and lifestyle, thus demanding modularity and/or customizability of various prosthesis components and characteristics, such as the dimensions, socket fit, and cosmetics.

- Versatility and adaptability are essential TFP user needs, which may be fulfilled by a combination of modular TFP designs and intelligent adaptive control algorithms, enabling device personalization based individual user capabilities and priorities. 
- The potential value of active (e. positive power) assistance in a TFP is well recognized by all types of TFP users, with assistance desired preferentially during moments of instability, stair/incline ascent, and higher-velocity walking.

- To improve comfort and minimize skin problems, the ideal TFP socket design should enable routine modulation of shape and/or volume to accommodate changes in residual limb volume and tissue properties, in addition to regulating temperature and humidity.

- The minimization of prosthesis weight remains an important design objective.

- Cost remains a limiting factor in prosthesis selection for many TFAs, thus highlighting lower-cost approaches to improving TFP performance as an area of high clinical impact.

To fulfill these requirements in the development of future TFP systems, they should be used by TFP researchers and developers as design inputs to a rigorous user-centered design framework such as that proposed by Beckerle and colleagues (21), which posits a systematic process for merging human and technical factors in the design of advanced lower limb prostheses, with particular attention to TFP.

In addition to the above recommendations regarding TFP design characteristics, the present study reveals several valuable insights regarding the human-centered design process. First, the survey's ranking of user design prioritizes without any corresponding measures of relative priority weighting favored the delineation between TFP features of similar priority, with the tradeoff of reducing the power to evaluate the absolute importance of specific design features. Second, survey questions regarding subjects' functional capabilities were phrased in terms of subjective satisfaction and autonomy, making them imprecise as indicators of absolute functionality. Though this perspective is suitable for a user-centered design process that holds user satisfaction and wellbeing as its ultimate objectives, subsequent TFP research and development efforts should further investigate the relationship between specific design characteristics, objective functional performance, usability, and user satisfaction.

\section{E. Study Limitations}

While supportive of the current clinical understanding that more advanced TFPs promote higher levels of user mobility, function, and overall health, this study's central findings of higher overall function and satisfaction among MPK relative to NMPK users must be interpreted within the context of two main study limitations. Most notably, owing to the survey's limited characterization of numerous health-related co-factors such as participants' overall health, condition of the intact limb, pre-amputation lifestyle, and baseline functional abilities (as quantified by standard clinical measures such as the Klevel or functional assessment scales), the study was not able to conduct a thoroughly controlled test of the hypothesis that MPKs confer independent improvements in outcomes relative to NMPKs. Irrespective of these survey-specific constraints, it remains likely that the effects of MPK-TFPs on clinical and personal outcomes cannot be thoroughly isolated from general health and human factors even by controlling for primary indicators of such factors, due to the number and the limited quantifiability of personal factors that influence prosthesis selection.

Second, the aforementioned recruitment bias towards traumatic TFAs limits the generalizability of full-sample analyses to the general TFA population. Moreover, the primary study site (INAIL Centro Protesi) is the leading orthopedic rehabilitation center in Italy, where the intensive, integrative standard of care creates a patient population likely more functionally advanced and engaged with their prostheses than the global TFA population. This center's standard care practice of prescribing MPKs following outfitting and initial rehabilitation with an NMPK-TFP MPKs may introduce an additional "healthy user bias" (43) among MPK users. While healthier users are presumably able to achieve the best functional outcomes from advanced TFPs, it remains possible that such devices could have the greatest marginal benefit for users with lower baseline abilities, as suggested by autonomy data among non-traumatic amputees (Table 5). Nonetheless, this study's heavy representation of traumatic amputees and MPK users is well-suited to the study's objective of evaluating user needs and priorities for the development of an advanced, actively powered TFP.

Page $18 / 25$ 


\section{F. Conclusions}

This study provides an extensive new characterization of transfemoral amputees (TFAs), encompassing their demographic and clinical characteristics, psychosocial attitudes and lifestyles, functionality and satisfaction with their current prostheses, and user needs and priorities for an ideal transfemoral prosthesis (TFP). Overall, users of TFPs with microprocessor-controlled knee units (MPKs) reported higher levels of activity, prosthesis use, and functional ability compared to those with NMPKs, corresponding to higher satisfaction and greater functional autonomy. While likely reflective of differences between MPK and NMPK users in terms of age and amputation etiology (and thus, overall health), these results reinforce the hypothesis that more advanced, actively controlled TFPs positively influence not only the safety and functional mobility of TFAs, but their overall sense of prosthesis acceptance and ownership, personal autonomy, and overall health and wellbeing. Based on past and present findings, it may be reasonably generalized that advanced TFP functionality, in conjunction with a variety of underlying clinical and personal factors, plays a significant role in enabling, maintaining, and/or reinforcing healthy mobility and lifestyle among TFAs.

Finally, a set of user-based design principles are synthesized based on survey data analysis. Future investigations should continue to develop, validate, and standardize measures of the functional abilities and personal priorities of TFAs, based on this study's survey and findings. In this way, this study may serve as a foundation to build a clinical evaluation tool to optimally select and configure TFPs to fulfill the needs of individual users.

\section{Abbreviations}

- AA - Active Assistance

- $A D L$ - Activities of Daily Living

- IQR - Inter-Quartile Range

- MPK - MicroProcessor-controlled Knee unit

- NMPK - Non-MicroProcessor-controlled Knee

- Pr-AA - Priorities for activities during which to receive Active Assistance from an ideal prosthesis

- Pr-GC - Priorities for General Characteristics of an ideal prosthesis

- Pr-Fn - Priorities for the mobility-related Functionality of an ideal prosthesis

- Pr-S - Priorities regarding the Socket of an ideal prosthesis

- SACH - Solid Ankle, Cushioned Heel

- TFA - TransFemoral Amputee

- TFP - TransFemoral Prosthesis

\section{Declarations}

\section{Ethics approval and consent to participate}

All study procedures, including subject recruitment and written informed consent, were pre-approved by the designated ethics committee for the study sites, in conformance with all pertinent institutional protocols and the 1964 Declaration of Helsinki. The specific study approval information is as follows:

- Ethics Committee: Comitato Etico di Area Vasta Emilia Centro della Regione Emiglia-Romagna (CE-AVEC)

- Study Reference No. 105/2018/OSS/AUSLBO

\section{Consent for publication}


Not applicable - the present manuscript does not contain or present data from any individual person.

\section{Availability of data and materials}

The dataset supporting the conclusions of this article is not publicly available due to subject privacy considerations (per ethics committee approval) but may be obtained from the corresponding author upon reasonable request.

\section{Competing Interests}

Beyond the official MOTU study funding noted below, additional sources of support and potential perceived conflicts of interest for specific authors include the following:

- One of the senior authors (NV) receives personal fees as a co-founder, advisor, and member of a wearable robotics business (IUVO SRL, university spin-off)

- Additional authors (SC, NV, AB) are listed as inventors in a series of pending patents in the domain of wearable robotics.

Apart from these instances noted above, each remaining author declares that they have no competing interests, both financial and non-financial.

\section{Study Funding}

This work was supported by INAIL, the Italian National Institute for Insurance against Work-related Injuries (non-commercial entity), within the PPRAI-MOTU (Protesi robotica di Arto Inferiore con sMart sOcket ed inTerfaccia bidirezionale per ampUtati di arto inferiore) project framework. INAIL-affiliated authors participated in the scientific review and approval of the study scope and objectives as well as final manuscript review (as detailed in the Authors' contributions), and an INAIL facility (Centro Protesi, Budrio, Bologna) served as a site of patient enrollment and survey administration.

\section{Authors' contributions}

The authors of this work have made substantial contributions to the following aspects of study design, execution, analysis, and manuscript preparation, respectively:

- Senior authorship: RS, AD, SC, NV and EG conceived and scientifically supervised the study

- $\mathrm{CF}, \mathrm{AB}, \mathrm{LP}, \mathrm{ER}$, and EG contributed to the conception and design of the work through their drafting of the study questionnaire;

- $\mathrm{GM}, \mathrm{ML}, \mathrm{LDM}, \mathrm{VM}, \mathrm{AM}, \mathrm{LR}, \mathrm{FT}$ critically reviewed the questionnaire;

- CF and LR participated in the acquisition of data;

- All authors contributed to the interpretation of survey data;

- All authors actively participated in the substantial review and revision of this work;

- Co-first authorship: CF and ZM performed the primary analysis and interpretation of survey data, were responsible for the primary drafting and extensive revision of the manuscript, and wish to be indicated as co-first authors;

In addition to their above contributions, all authors have read and approved the submitted version of this manuscript, as well as all major previous versions that preceded it. Further, all authors have hereby agreed both to be personally accountable for their own contributions and to ensure that potential questions related to the accuracy or integrity of any 
part of the work, including those in which the author was not personally involved, are appropriately investigated, resolved, and the resolution documented in the literature.

\section{References}

1. Dunne S, Coffey L, Gallagher P, Desmond D. "If I can do it I will do it, if I can't, I can't": A study of adaptive self-regulatory strategies following lower limb amputation. Disabil Rehabil. 2014;36(23):1990-7.

2. Marino M, Pattni S, Greenberg M, Miller A, Hocker E, Ritter S, et al. Access to prosthetic devices in developing countries: Pathways and challenges. Proc 5th IEEE Glob Humanit Technol Conf GHTC 2015. 2015;45-51.

3. Windrich M, Grimmer M, Christ O, Rinderknecht S, Beckerle P. Active lower limb prosthetics: A systematic review of design issues and solutions. Biomed Eng Online. 2016;15(3):5-19.

4. Dillingham TR, Pezzin LE, MacKenzie EJ. Limb amputation and limb deficiency: Epidemiology and recent trends in the United States. South Med J [Internet]. 2002 [cited 2020 Apr 9];95(8):875-83. Available from:

https://www.ncbi.nlm.nih.gov/pubmed/12190225

5. Herr HM, Grabowski AM. Bionic ankle-foot prosthesis normalizes walking gait for persons with leg amputation. Proc $R$ Soc B Biol Sci [Internet]. 2012 [cited 2020 Aug 28];279(1728):457-64. Available from: /pmc/articles/PMC3234569/? report=abstract

6. Össur - PROPRIO FOOT ® [Internet]. [cited 2020 Aug 28]. Available from: https://www.ossur.com/enus/prosthetics/feet/proprio-foot

7. C-Leg above knee prosthetic leg - Ottobock US [Internet]. [cited 2020 Aug 28]. Available from: https://www.ottobockus.com/prosthetics/lower-limb-prosthetics/solution-overview/c-leg-above-knee-system/

8. Össur - RHEO KNEE ® [Internet]. [cited 2020 Aug 28]. Available from: https://www.ossur.com/enus/prosthetics/knees/rheo-knee

9. Genium leg prosthesis - Ottobock US [Internet]. [cited 2020 Aug 28]. Available from: https://www.ottobockus.com/prosthetics/lower-limb-prosthetics/solution-overview/genium-above-knee-system/

10. Össur - POWER KNEE (TM) [Internet]. [cited 2020 Aug 28]. Available from: https://www.ossur.com/enus/prosthetics/knees/power-knee

11. Baars EC, Schrier E, Dljkstra PU, Geertzen JHB. Prosthesis satisfaction in lower limb amputees: A systematic review of associated factors and questionnaires [Internet]. Vol. 97, Medicine (United States). Lippincott Williams and Wilkins; 2018 [cited 2020 Aug 28]. Available from: https://pubmed.ncbi.nlm.nih.gov/30278503/

12. Lansade C, Vicaut E, Paysant J, Ménager D, Cristina MC, Braatz F, et al. Mobility and satisfaction with a microprocessorcontrolled knee in moderately active amputees: A multi-centric randomized crossover trial. Ann Phys Rehabil Med. 2018;61(5):278-85.

13. Van De Meent H, Hopman MT, Frölke JP. Walking ability and quality of life in subjects with transfemoral amputation: A comparison of osseointegration with socket prostheses. Arch Phys Med Rehabil. 2013;94:2174-8.

14. Schaffalitzky E, Gallagher P, MacLachlan M, Ryall N. Understanding the benefits of prosthetic prescription: Exploring the experiences of practitioners and lower limb prosthetic users. Disabil Rehabil. 2011;33(15-16):1314-23.

15. Kapti AO, Yucenur MS. Design and control of an active artificial knee joint. Mech Mach Theory. 2006;41(12):1477-85.

16. Heller BW, Datta D, Howitt J. A pilot study comparing the cognitive demand of walking for transfemoral amputees using the intelligent prosthesis with that using conventionally damped knees. Clin Rehabil [Internet]. 2000 Oct [cited 2020 Apr 9];14(5):518-22. Available from: http://www.ncbi.nlm.nih.gov/pubmed/11043877

17. Boonstra AM, Schrama J, Fidler V, Eisma WH. Energy cost during ambulation in transfemoral amputees: A knee joint with a mechanical swing phase control vs a knee joint with a pneumatic swing phase control. Scand J Rehabil Med. 1995;27(2):77-81.

Page 21/25 
18. Linde H van der, Hofstad CJ, Geurts ACH, Postema K, Geertzen JHB, Limbeek J van. A systematic literature review of the effect of different prosthetic components on human functioning with a lower-limb prosthesis. J Rehabil Res Dev [Internet]. 2004;41(4):555. Available from: http://www.rehab.research.va.gov/jour/04/41/4/vanderlinde.html

19. Cairns N, Murray K, Corney J, McFadyen A. Satisfaction with cosmesis and priorities for cosmesis design reported by lower limb amputees in the United Kingdom: Instrument development and results. Prosthet Orthot Int. 2014;38(6):46773.

20. Abu Osman NA, Eshraghi A, Gholizadeh H, Wan Abas WAB, Lechler K. Prosthesis donning and doffing questionnaire: Development and validation. Prosthet Orthot Int. 2017;

21. Beckerle P, Christ O, Schürmann T, Vogt J, von Stryk O, Rinderknecht S. A human-machine-centered design method for (powered) lower limb prosthetics. Rob Auton Syst [Internet]. 2017;95:1-12. Available from: http://dx.doi.org/10.1016/j.robot.2017.05.004

22. Cordella F, Ciancio AL, Sacchetti R, Davalli A, Cutti AG, Guglielmelli E, et al. Literature review on needs of upper limb prosthesis users. Front Neurosci. 2016;10(MAY):1-14.

23. Desmond DM, MacLachlan M. Factor structure of the Trinity Amputation and Prosthesis Experience Scales (TAPES) with individuals with acquired upper limb amputations [Internet]. Vol. 84, American Journal of Physical Medicine and Rehabilitation. Am J Phys Med Rehabil; 2005 [cited 2020 Aug 5]. p. 506-13. Available from:

https://pubmed.ncbi.nlm.nih.gov/15973087/

24. Hagberg Kerstin ; Brånemark R, Hägg Olle. Questionnaire for Persons with a Transfemoral Amputation (Q-TFA): initial validity and reliability of a new outcome measure - PubMed. J Rehabil Res Dev [Internet]. 2004 Sep [cited 2020 Aug 5];41(5):695-706. Available from: https://pubmed.ncbi.nlm.nih.gov/15558399/

25. Heinemann AW, Bode RK, O'Reilly C. Development and measurement properties of the Orthotics and Prosthetics User's Survey (OPUS): A comprehensive set of clinical outcome instruments [Internet]. Vol. 27, Prosthetics and Orthotics International. International Society for Prosthetics and Orthotics (ISPO); 2003 [cited 2020 Aug 5]. p. 191-206. Available from: https://pubmed.ncbi.nlm.nih.gov/14727700/

26. Bravini E, Franchignoni F, Ferriero G, Giordano A, Bakhsh H, Sartorio F, et al. Validation of the Italian version of the client satisfaction with device module of the orthotics and prosthetics users' survey. Disabil Health J [Internet]. 2014 [cited 2020 Aug 5];7(4):442-7. Available from: https://pubmed.ncbi.nlm.nih.gov/25224984/

27. Legro MW, Reiber GD, Smith DG, Del Aguila M, Larsen J, Boone D. Prosthesis evaluation questionnaire for persons with lower limb amputations: Assessing prosthesis-related quality of life. Arch Phys Med Rehabil [Internet]. 1998 [cited 2020 Aug 5];79(8):931-8. Available from: https://pubmed.ncbi.nlm.nih.gov/9710165/

28. Braun V, Clarke V. Braun, V. and Clarke, V. (2006) Using thematic analysis in psychology. Qualitative Research in Psychology, 3 (2). pp. 77-101. ISSN 1478-0887 Available from: http://eprints.uwe.ac.uk/11735. Qual Res Psychol [Internet]. 2006;3(2):77-101. Available from: http://eprints.uwe.ac.uk/11735\%5Cnhttp://eprints.uwe.ac.uk/11735

29. McCollum P, Raza Z. Vascular disease: limb salvage versus amputation. In: Atlas of amputations and limb deficiencies surgical prosthetic and rehabilitation principles. 3rd ed. Rosemont, IL: American Academy of Orthopaedic Surgeons; 2004. p. 31-45.

30. Gauthier-Gagnon C, Grisé M-C, Potvin D. Predisposing factors related to prosthetic use by people with a transtibial and transfemoral amputation. Predisposing factors Relat to Prosthet use by people with a transtibial transfemoral amputation [Internet]. 1998;10(4):99-109. Available from:

https://journals.Iww.com/jpojournal/Abstract/1998/01040/Predisposing_Factors_Related_to_Prosthetic_Use_by.6.aspx

31. Legro MW, Reiber G, Del Aguila MD, Ajax MJ, Boone DA, Larsen JA, et al. Issues of importance reported by persons with lower limb amputations and prostheses. J Rehabil Res Dev. 1999 Jul;36(3):155-63.

32. Biddiss E, Beaton D, Chau T. Consumer design priorities for upper limb prosthetics. Disabil Rehabil Assist Technol. 2007;2(6):346-57. 
33. Vanicek N, Strike SC, McNaughton L, Polman R. Lower limb kinematic and kinetic differences between transtibial amputee fallers and non-fallers. Prosthet Orthot Int [Internet]. 2010 Dec [cited 2016 Aug 11];34(4):399-410. Available from: http://www.ncbi.nlm.nih.gov/pubmed/20450461

34. Schafer ZA, Perry JL, Vanicek N. A personalised exercise programme for individuals with lower limb amputation reduces falls and improves gait biomechanics: A block randomised controlled trial. Gait Posture [Internet]. 2018;63(September 2017):282-9. Available from: https://doi.org/10.1016/j.gaitpost.2018.04.030

35. Chen JL, Gu DY. Local dynamic stability of lower extremity joints in lower limb amputees during slope walking. Proc Annu Int Conf IEEE Eng Med Biol Soc EMBS. 2013;7241-4.

36. Sheehan RC, Gottschall JS. At similar angles, slope walking has a greater fall risk than stair walking. Appl Ergon [Internet]. 2012;43(3):473-8. Available from: http://dx.doi.org/10.1016/j.apergo.2011.07.004

37. Hafner BJ, Willingham LL, Buell NC, Allyn KJ, Smith DG. Evaluation of Function, Performance, and Preference as Transfemoral Amputees Transition From Mechanical to Microprocessor Control of the Prosthetic Knee. Arch Phys Med Rehabil. 2007;88(2):207-17.

38. Kahle JT. Comparison of nonmicroprocessor knee mechanism versus C-Leg on Prosthesis Evaluation Questionnaire, stumbles, falls, walking tests, stair descent, and knee preference. J Rehabil Res Dev [Internet]. 2008;45(1):1-14. Available from: http://www.rehab.research.va.gov/jour/08/45/1/pdf/kahle.pdf

39. Grimmer M, Seyfarth A. Mimicking human-like leg function in prosthetic limbs. In: Neuro-robotics: from brain machine interfaces to rehabilitation robotics [Internet]. 2014. p. 18-74. Available from: http://link.springer.com/10.1007/978-94017-8932-5

40. Segal AD, Orendurff MS, Klute GK, McDowell ML, Pecoraro JA, Shofer J, et al. Kinematic and kinetic comparisons of transfemoral amputee gait using C-Leg and Mauch SNS prosthetic knees. J Rehabil Res Dev [Internet]. 2006;43(7):857. Available from: http://www.rehab.research.va.gov/jour/06/43/7/pdf/segal.pdf

41. Christ O, Jokisch M, Preller J, Beckerle P, Wojtusch J, Rinderknecht S, et al. User-centered prosthetic development: Comprehension of amputees' needs. Biomed Tech. 2012;57(SUPPL. 1 TRACK-R):1098-101.

42. Hochberg LR, Anderson KD. BCl users and their needs. In: Wolpaw JR, Wolpaw EW, editors. Brain-Computer Interfaces: Principles and Practice. 1st ed. Oxford: Oxford University Press; 2012.

43. Shrank WH, Patrick AR, Brookhart MA. Healthy user and related biases in observational studies of preventive interventions: A primer for physicians. Vol. 26, Journal of General Internal Medicine. 2011. p. 546-50.

\section{Figures}

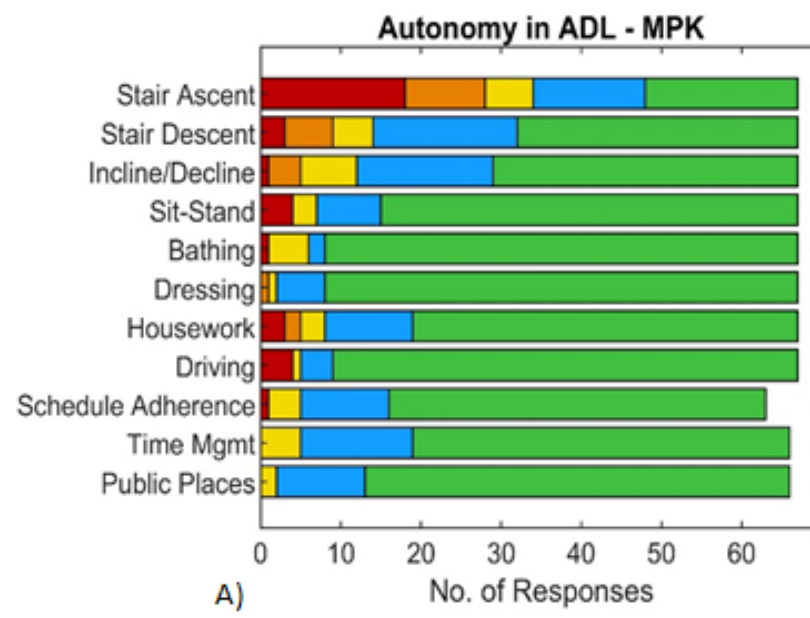

A)

\begin{tabular}{cc} 
& med (IQR) \\
MPK & NMPK \\
\hline$-3(5)$ & $2(3)$ \\
$-6(2)$ & $1(3)$ \\
$-6(2)$ & $3(2)$ \\
$-6(0)$ & $4(4)$ \\
$-6(0)$ & $6(3)$ \\
$-6(0)$ & $6(2)$ \\
$-6(2)$ & $4(3.5)$ \\
$-6(0)$ & $6(4.75)$ \\
$-6(2)$ & $6(3)$ \\
$-6(2)$ & $4(3)$ \\
$-6(0)$ & $4(3.75)$ \\
Aggregate \\
$6(0)$ & $4(4)$ \\
\multicolumn{3}{c}{ B } \\
\multicolumn{3}{c}{ B) }
\end{tabular}

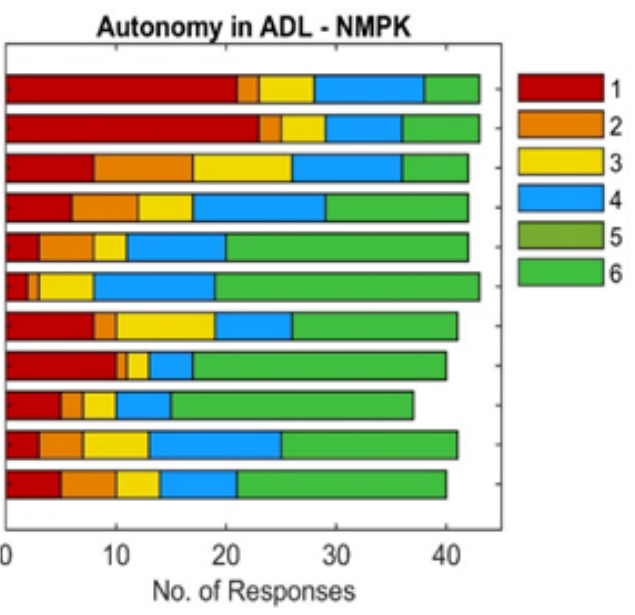

Figure 1 
Autonomy in activities of daily living (ADL): Distribution of Likert scale responses, ranging from "completely autonomous" (6) to "completely non-autonomous [fully dependent]" (1) for each task in A) MPK and B) NMPK users. *: Aggregate autonomy computed as the median (IQR) of each subject's median autonomy across all
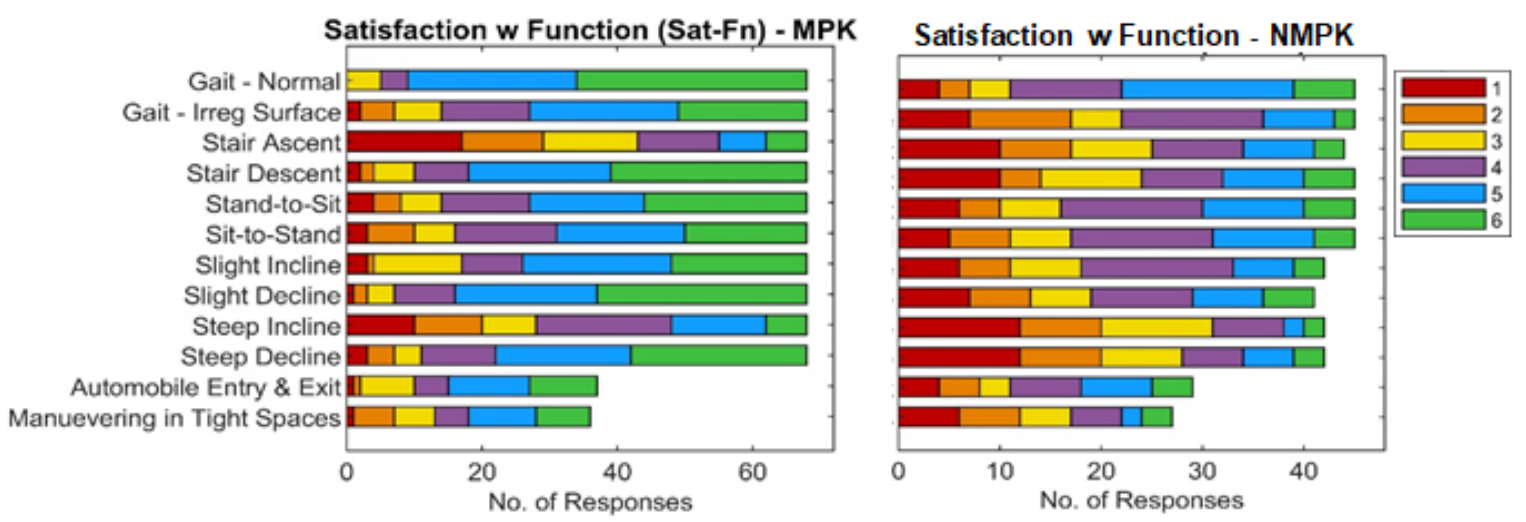

\section{Figure 2}

Satisfaction with Prosthesis Functionality in ADL in A) all MPK and B) all NMPK users (traumatic + non-traumatic). Likert scale responses range from "completely satisfied" (6) to "completely dissatisfied" (1). Corresponding summary data reported in Table 7.

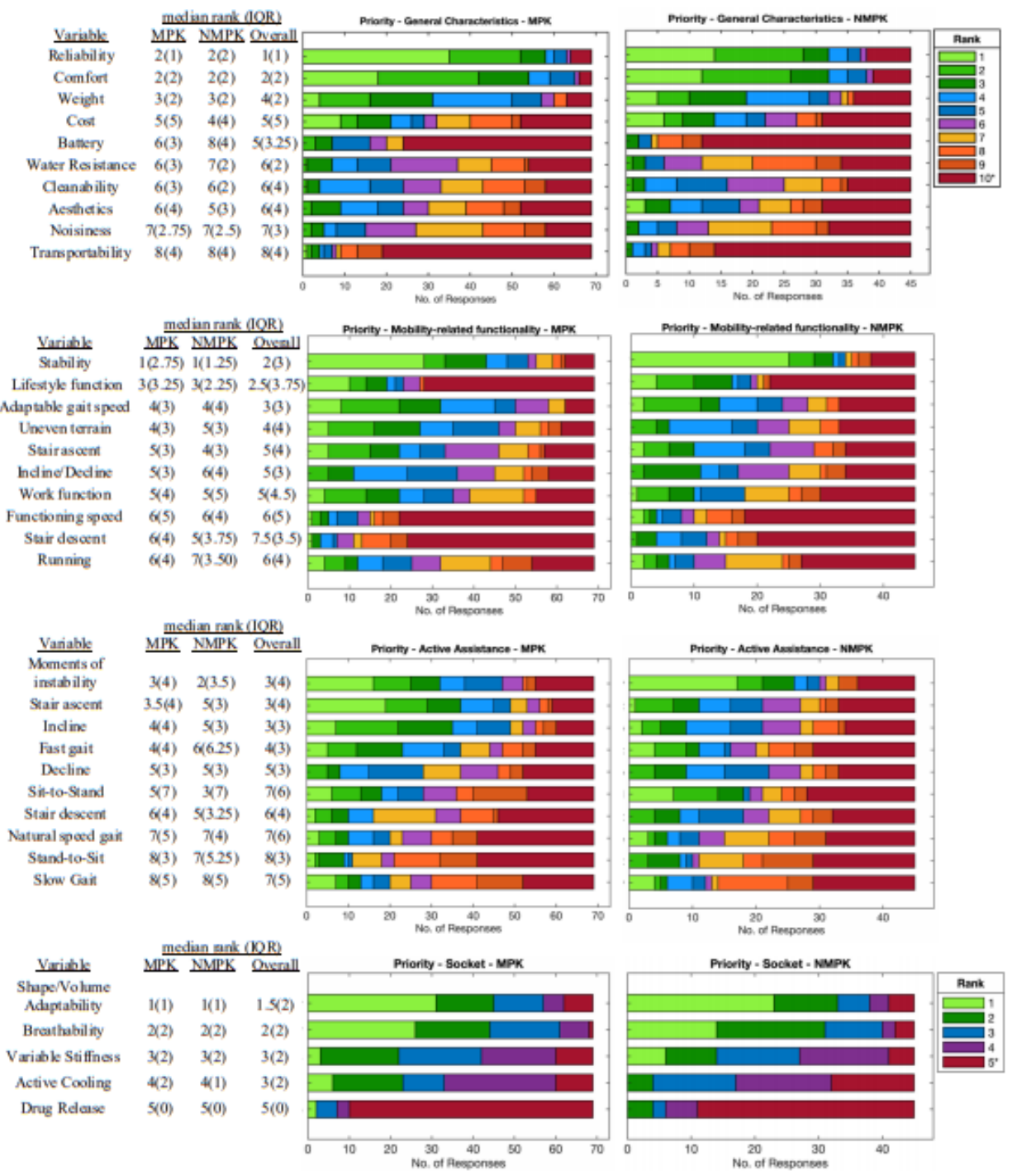




\section{Figure 3}

Design priorities for an ideal transfemoral prosthesis (TFP): *: missing responses were imputed the lowest rank value in each category (10 for general characteristics, mobility-related function, and active assistance, and 5 for the socket).

\section{Supplementary Files}

This is a list of supplementary files associated with this preprint. Click to download.

- STROBEchecklistJNER.doc 